\title{
Enterocolite necrosante e hemotransfusão: qual a relação?
}

\section{Necrotizing enterocolitis and blood transfusion: how are they related?}

\author{
Henrique Augusto Lino, ${ }^{1}$ Higor Kenedy Ramos, ${ }^{1}$ Maria Amália de Miranda Pereira ${ }^{2}$ e Síura Aparecida Borges \\ Silva ${ }^{1,2}$ \\ 'Universidade de Itaúna \\ ${ }^{2}$ Hospital-Maternidade Odete Valadares
}

\section{Palavras-chave:}

Enterocolite necrosante; Transfusão de sangue; Fatores de risco.

\section{Resumo}

Introdução: a enterocolite necrosante é uma emergência pediátrica multifatorial, existindo controvérsias sobre o papel das transfusões sanguíneas em sua etiopatogenia. Objetivo: nosso objetivo foi descrever dois casos nos quais se observou uma relação temporal consistente entre as transfusões e o desenvolvimento da doença, ou seja, em até 48 horas após a transfusão. Descrição do caso: nos dois casos abordados, os neonatos apresentavam níveis baixos de hemoglobina e evoluíram para enterocolite necrosante após a administração do concentrado de hemácias. O neonato 1 apresentou distensão abdominal e sinais de instabilidade hemodinâmica cinco horas após a transfusão. Radiografia abdominal evidenciou distensão de alças, áreas sugestivas de pneumatose intestinal e alça fixa, com indicação de laparotomia exploradora. O neonato 2, decorridas oito horas da transfusão, apresentou distensão abdominal e instabilidade hemodinâmica súbita grave e refratária ao tratamento, o que levou o paciente a óbito. À radiografia, observou-se pneumatose intestinal. Discussão: não está definido na literatura se a anemia pré-estabelecida ou a transfusão são elementos da patogenia ou apenas marcadores de enterocolite necrosante iminente. O acompanhamento dos casos apresentados sugere que pacientes com fatores de risco para a condição sejam observados de forma rigorosa nas primeiras 48 horas após uma transfusão, com o objetivo de detectar precocemente sinais sugestivos da doença e iniciar-se seu tratamento imediatamente.

\section{Keywords:}

Enterocolitis, necrotizing; Blood transfusion; Risk factors.

\begin{abstract}
Introduction: the necrotizing enterocolitis is a multifatorial pediatric emergency and there is controversy regarding the role of blood transfusions in its development. Objective: our objective was to describe two cases in which a consistent temporal relationship between transfusions and the disease development was observed, in other words, up to 48 hours after a transfusion. Case description: in our two cases, the neonates had low hemoglobin levels and developed necrotizing enterocolitis between 5 to 12 hours after the blood transfusion. The neonate 1 presented abdominal distension and shock signs, about five hours after the transfusion. Abdominal radiography evidenced loop distension, some suggestive areas of intestinal pneumatosis and fixed loops. This neonate underwent a diagnostic laparotomy. The neonate 2, about eight hours after the transfusion, presented significant abdominal distension and developed sudden and severe shock. The radiography showed intestinal pneumatosis. Discussion: There is controversy in whether the pre-established anemia or the transfusion are elements of the pathogenesis of necrotizing enterocolitis or whether they are markers of the imminent disease. Our case reports suggest that high risk neonates should be strictly observed in the first 48 hours after blood transfusion, to detect early signs of disease and to start treatment immediately, despite the actual pathogenesis of necrotizing enterocolitis.
\end{abstract}




\section{INTRODUÇÃO}

A enterocolite necrosante (ECN) é uma emergência gastrointestinal comum no período neonatal. Caracteriza-se por sinais e sintomas gastrointestinais e sistêmicos de intensidade variável, decorrentes de lesões inflamatórias na mucosa ou parede de alças intestinais, com potencial progressão para necrose e perfurações, mais comumente no íleo terminal, colo ascendente e parte proximal do colo transverso.

Essa condição clínica incide sobre 1-3/1.000 nascimentos e sobre $1-8 \%$ dos recém-nascidos (RN) em unidades de terapia intensiva neonatal (UTIN). ${ }^{1}$ Ela pode ocorrer em até $4-15 \%$ dos neonatos pequenos para a idade gestacional e sobre mais de $11 \%$ dos neonatos nascidos com menos de 750 gramas. Sua incidência também é inversamente proporcional à idade gestacional (IG), sendo rara em gestações a termo. ${ }^{1,2}$

Dentre os principais fatores de risco para desenvolvimento da ECN estão a prematuridade, colonização bacteriana, alimentação enteral, hipóxia ou aporte sanguíneo intestinal alterado. ${ }^{1}$ Os fatores pré-natais relacionam-se fundamentalmente aos eventos relacionados a hipoperfusão tecidual, inflamação da mucosa e lesão vascular. Os fatores intraparto podem contribuir potencialmente para a injúria isquêmica e facilitar a exposição bacteriana. Os fatores pós-natais, por fim, relacionam-se à colonização bacteriana alterada, deficiência de micronutrientes e lesão da mucosa intestinal. ${ }^{2}$ Transfusões e exsanguinotransfusões também foram associadas ao desenvolvimento de ECN em diversos estudos. ${ }^{1}$

A presente discussão tem por objetivo descrever dois casos nos quais se observou uma relação temporal entre as transfusões e o desenvolvimento de ECN, ou seja, até 48 horas após a transfusão, em uma UTIN-referência em alto risco obstétrico e neonatal no estado de Minas Gerais.

\section{DESCRIÇÃO DO CASO}

A seguir descrevemos os casos observados.

\section{CASO 1}

RN pré-termo do sexo feminino, adequada para a IG, muito baixo peso, com 28 semanas pela data da última menstruação, primeira gemelar, nascida de parto vaginal, com peso de nascimento de 915 gramas. Foi admitida na UTIN em questão com 48 horas de vida, encaminhada do interior do estado de Minas Gerais. Relato de intubação orotraqueal na sala de parto, por dificuldade respiratória precoce (Apgar 7 e 8), tendo recebido surfactante com 5 horas de vida. Na UTIN, apresentou quadro clinicorradiológico compatível com doença da membrana hialina moderada, sendo possível a extubação após cinco dias. Apresentou sepse neonatal precoce presumida, com acometimento do sistema nervoso central, tratada por 21 dias com cefotaxima. Diagnosticada persistência do canal arterial (PCA), sendo tratada com um ciclo de paracetamol. À ultrassonografia transfontanela, apresentou hemorragia peri-intraventricular grau I à esquerda e grau II à direita, reabsorvidas.

Após extubação, no sexto dia, manteve-se em uso de pressão positiva contínua nas vias aéreas (CPAP). Evoluiu com estabilidade respiratória, boa tolerância alimentar até por volta de 30 dias de idade cronológica, quando apresentou episódios frequentes de queda de saturação de oxigênio. Descartada infecção, devido a leucograma normal, proteína $\mathrm{C}$ reativa negativa e hemocultura sem crescimento, verificaram-se níveis de hemoglobina de $6,8 \mathrm{~g} / \mathrm{dl}$, compatível com o quadro clínico. Nesse momento, recebia dieta plena conforme a rotina da unidade, sendo indicada hemotransfusão, em duas administrações de $10 \mathrm{ml} / \mathrm{kg}$ a cada 24 horas. Após cinco horas da primeira etapa da transfusão, a RN apresentou distensão abdominal importante e piora do estado geral, com sinais de instabilidade hemodinâmica, constatada por pulso filiforme, taquicardia, palidez e perfusão capilar lentificada. Foi submetida à intubação orotraqueal, iniciadas dopamina, dobutamina e antimicrobianos, inicialmente oxacilina e amicacina, com posterior substituição da oxacilina por clindamicina. Radiografia abdominal evidenciou distensão de alças, áreas sugestivas de pneumatose intestinal e alça fixa, com indicação de laparotomia exploradora. Quadro de ECN compatível com a classificação IIB de Bell. Em 48 horas, após estabilização clínica, realizou-se abordagem cirúrgica, com ressecção de $20 \mathrm{~cm}$ de intestino necrosado e realizado ileostomia. A hemocultura não mostrou crescimento bacteriano.

Paciente evoluiu com melhora gradual do quadro, permanecendo com dieta suspensa por duas semanas e antibioticoterapia por 14 dias. Após estabilização clínica e das comorbidades associadas à prematuridade, foi realizada anastomose da ileostomia, tendo recebido alta hospitalar com estabilidade clínica.

\section{CASO 2}

RN pré-termo, feminino, adequada para a IG, muito baixo peso, com 25 semanas e um dia por ultrassom de segundo trimestre, segunda gemelar, nascida de parto vaginal, apresentação pélvica, com peso de nascimento de 846 gramas. Nasceu deprimida e bradicárdica, com 
necessidade de intubação orotraqueal em sala de parto (Apgar 4 e 6). Admitida na UTIN em questão com doença da membrana hialina grave, recebendo surfactante com duas horas de vida e melhora clinicorradiológica. Permaneceu em ventilação mecânica por 14 dias, evoluindo para ventilação não invasiva. Apresentou sepse neonatal tardia, com hemocultura positiva para E. coli, Klebsiella $s p$ multissensíveis e acometimento do sistema nervoso central. Abordada inicialmente com oxacilina e gentamicina, posteriormente substituídos por cefotaxima, durante 21 dias, conforme antibiograma. Foi diagnosticada PCA sem repercussões hemodinâmicas, porém refratária ao tratamento clínico, optando-se por conduta expectante. À ultrassonografia transfontanela evidenciou-se hemorragia peri-intraventricular grau I à esquerda, posteriormente reabsorvida.

Após tratamento do episódio infeccioso, evoluiu com estabilidade respiratória, boa tolerância alimentar até por volta de 29 dias de idade cronológica, quando apresentou episódios frequentes de queda de saturação de oxigênio já em CPAP, sem melhora com ventilação não invasiva. Foi realizado rastreio infeccioso, com leucograma normal, proteína $\mathrm{C}$ reativa negativa e hemocultura sem crescimento, além de verificados níveis de hemoglobina de $8,5 \mathrm{~g} / \mathrm{dl}$, que justificaria as quedas persistentes de saturação. Na ocasião, aos 29 dias de vida e já recebendo dieta plena conforme a rotina da unidade, indicou-se hemotransfusão, em duas etapas de $10 \mathrm{ml} /$ $\mathrm{kg}$ a cada 24 horas.

Decorridas oito horas da primeira etapa da transfusão, a RN apresentou distensão abdominal importante, apneias, hipoatividade e instabilidade hemodinâmica súbita grave e refratária ao tratamento instituído. Foram iniciadas dopamina e dobutamina, vancomicina e amicacina. À radiografia abdominal, observou-se pneumatose intestinal. Paciente foi a óbito após cinco horas do início dos sintomas, presumindo-se o diagnóstico de ECN fulminante. À hemocultura houve crescimento de Enterococcus $s p$ e Acinetobacter baumannii multissensível.

\section{SOBRE OS PROTOCOLOS DA UTIN}

Na UTIN, a ECN é inicialmente abordada com oxacilina e amicacina. Evidenciando-se sinais de instabilidade clínica, opta-se por vancomicina e amicacina. Em casos com sinais de perfuração, acrescenta-se a cobertura de anaeróbios com clindamicina ou metronidazol. Cefalosporinas de terceira e quarta geração são indicadas em caso de ausência de resposta clínica e/ou se há alteração liquórica. Carbapenêmicos (meropenem) são indicados se suspeita/confirmação do envolvimento de germes Gram-negativos multirresistentes.

A rotina de hemotransfusões preconiza uso de hemácias deleucotizadas e filtro de leucócitos para todos os casos, sendo que os níveis indicativos de transfusão são individualizados, conforme a apresentação clínica do RN. Quando indicada, utiliza-se o volume de $20 \mathrm{ml} / \mathrm{kg}$, dividido em duas administrações durante duas horas, a cada 24 horas, fora do horário das dietas.

Na unidade, um ecocardiograma é realizado de rotina na primeira semana de vida em todo RN com peso de nascimento menor que 1.000 gramas e, acima desse peso, em caso de presença de sopro ao exame físico. A droga-padrão utilizada é a indometacina oral, na dose de $0,2 \mathrm{mg} / \mathrm{kg}$ em três administrações com intervalo de 12 horas. O paracetamol é usado quando há contraindicação ou ausência de resposta à indometacina.

\section{DISCUSSÃO}

Existem divergências sobre o real papel das transfusões sanguíneas no desenvolvimento de ECN. Não está definido ao certo se a causa é a anemia pré-estabelecida, se a transfusão tem um papel na sua patogenia ou se seria um marcador de ECN iminente. Essa controvérsia está presente na literatura há mais de três décadas, desde o relato de MGardy, em 1987, quando ocorreu um surto de ECN em sua UTIN. ${ }^{2}$

A base para essa controvérsia consiste na multiplicidade das causas da ECN. Enquanto alguns estudos sugerem que a transfusão causa uma hipoperfusão intestinal pós-prandial em determinados segmentos, a qual facilitaria a translocação bacteriana, ${ }^{3}$ outros autores afirmam que a patogenia é, na verdade, a anemia severa anterior à transfusão, causadora de isquemia transitória de alças intestinais e consequente translocação bacteriana. Dessa forma, esses neonatos que serão candidatos a receber transfusões desenvolvem ECN e, consequentemente, surge a transfusão como fator de confusão sobre a etiologia do processo. ${ }^{4,5}$ Em modelos animais, ${ }^{6}$ demonstrou-se que a anemia reduz o aporte sanguíneo intestinal, forçando os tecidos a aumentar a extração de oxigênio compensatoriamente, além de potencial efeito de atraso da maturação pós-natal da vasculatura esplâncnica, resultando em lesão isquêmica intestinal. . $^{5,7}$

Em outros estudos, neonatos pré-termo que recebem transfusão na presença de PCA apresentaram redução do fluxo mesentério em até quatro horas após a transfusão, a qual foi proporcional ao volume transfundido, também sugerindo que a fisiopatologia vai além da anemia., Em coorte com 111 neonatos pré-termo com ECN 
e 222 controles, Singh e Visintainer ${ }^{5}$ encontraram associação entre o menor hematócrito e a doença (odds ratio - OR - 1,1), porém no mesmo estudo também foi evidenciada a associação com as transfusões nas 24 horas (OR 7,6) e 46 horas (OR 5,5) anteriores ao diagnóstico.

Em ambos os casos abordados, as RN encontravam-se com níveis baixos de hemoglobina e evoluíram para ECN entre 5 e 12 horas após a administração do concentrado de hemácias. Nos casos relatados, os níveis indicativos de hemotransfusão foram 6,8 e 8,5 g/dl, ambos em RN com episódios de queda de saturação e em ventilação não invasiva.

Apesar de não ser comprovada a relação causal, há uma relação temporal, definida quando se desenvolveram sintomas dentro de 48 horas da hemotransfusão. Similarmente, outros estudos observacionais também encontraram uma associação temporal da transfusão com desenvolvimento de ECN grave., ${ }^{5,9}$ Outros estudos apontam que a associação é mais consistente após os primeiros dias de vida. ${ }^{3,8}$

O mecanismo exato é desconhecido, porém sugere-se que a exposição a mediadores ativos, como hemoglobina livre, citocinas e fragmentos celulares, pode causar uma reação imunológica na parede intestinal e deformabilidade reduzida das hemácias, adesão aumentada e menor concentração de óxido nítrico por armazenamento prolongado do sangue; presença de adjuvantes no hemoderivado, perda da responsividade vascular visceral à alimentação e reações imunológicas causando poliaglutinação também são teorias apontadas para a questão. ${ }^{10}$ Em contrapartida, outros desenhos de estudo sugerem um papel protetor das transfusões, indicando a anemia como um marcador de ECN. ${ }^{11,12}$ A tabela 1 resume os achados dos principais estudos de caso-controle e coorte, relacionando seu desenho, amostra e conclusão dos autores.

Ensaios clínicos randomizados também são discrepantes em relação aos achados. Por exemplo, Chen e colaboradores $^{13}$ encontraram um OR 2,84 para o risco de ECN pós-transfusional; os demais ensaios concluíram que a hemotransfusão era protetora, com OR de 1,67.,11 Sobre esse fato, Kirpalani e Zupancic ${ }^{11}$ sugerem que os resultados de ensaios clínicos randomizados apontando em direção oposta às séries de casos e outras metodologias sejam resultado de sua superioridade metodológica, sua maior amostra, menor número de fatores confundidores e menor viés de publicação. De forma similar, Alfaleh et $a l .{ }^{2}$ consideram que os estudos observacionais superestimam os riscos, sobretudo em desenhos de caso-controle. Mohamed e Shah, ${ }^{10}$ em uma metanálise com 12 estudos com risco moderado de vieses, também encontraram uma associação temporal entre a transfusão e ECN tanto

Tabela 1 - Resumo dos estudos de coorte e caso-controle recentes sobre a associação entre hemotransfusões e ECN

\begin{tabular}{|c|c|c|}
\hline Estudo & Desenho do estudo & Conclusão \\
\hline Alfaleh Ket al. ${ }^{2}$ & $\begin{array}{l}\text { Caso-controle retrospectivo com } 153 \\
\text { neonatos pré-termo de muito baixo peso }\end{array}$ & Transfusão foi protetora para ECN $(\mathrm{OR}=0,39 ; 95 \% \mathrm{IC}=0,18-0,84 ; \mathrm{p}=0,02)$ \\
\hline Christensen RD et al. ${ }^{3}$ & $\begin{array}{l}\text { Caso-controle retrospectivo com } 112 \\
\text { neonatos }\end{array}$ & $\begin{array}{l}\text { Transfusões foram mais frequentes no grupo que desenvolveu ECN; as } \\
\text { chances foram } 11,7 \text { vezes maiores em transfusões após o } 70 \text { dia de vida } \\
(\mathrm{OR}=2,17 \text { e } \mathrm{OR}=11,77 ; \mathrm{p}<0,001)\end{array}$ \\
\hline Singh R, Visintainer $\mathrm{PF}^{5}$ & $\begin{array}{l}\text { Caso-controle retrospectivo com } 333 \\
\text { neonatos pré-termo }\end{array}$ & $\begin{array}{l}\text { Há associação entre transfusão e ECN, sobretudo quando mais precoce } \\
(\mathrm{OR}=7,60 ; p=0,001)\end{array}$ \\
\hline Blau J et al. ${ }^{6}$ & $\begin{array}{l}\text { Coorte com } 256 \text { neonatos de muito } \\
\text { baixo peso de uma população de } 883 \\
\text { neonatos }\end{array}$ & $\begin{array}{l}\text { Existe associação entre hemotransfusão e ECN }\left(x^{2}=170,7\right. \\
d f=40 ; p<0,000001)\end{array}$ \\
\hline Josephson D et al. ${ }^{8}$ & $\begin{array}{l}\text { Caso-controle retrospectivo com } 93 \\
\text { neonatos pré-termo }\end{array}$ & $\begin{array}{l}\text { ECN tardia associou-se mais a transfusões que a precoce } \\
(\mathrm{OR}=6,7 ; 95 \% \mathrm{IC}=1,5-31,2 ; \mathrm{p}=0,02)\end{array}$ \\
\hline Sood BG et al. ${ }^{9}$ & $\begin{array}{l}\text { Coorte retrospectiva com } 627 \text { neonatos } \\
\text { pré-termo }\end{array}$ & Transfusões foram fator protetor para ECN $(p=0,000)$ \\
\hline Sharma $\mathrm{R}^{12}$ & $\begin{array}{l}\text { Caso-controle prospectivo com } 585 \\
\text { neonatos pré-termo }\end{array}$ & $\begin{array}{l}\text { Não identificou diferenças nas transfusões entre os grupos } \\
(H R=0,78 ; 95 \% I C=0,57-1,07 ; p=0,11)\end{array}$ \\
\hline Santos AM et al. ${ }^{14}$ & Coorte com 4.283 neonatos pré-termo & $\begin{array}{l}\text { Neonatos transfundidos tiveram maiores chances de desenvolver } \\
\mathrm{ECN}(\mathrm{OR}=3,80 ; 95 \% \mathrm{IC}=2,26-6,41)\end{array}$ \\
\hline Wallenstein MB et al. ${ }^{15}$ & $\begin{array}{l}\text { Coorte retrospectiva com } 414 \text { neonatos } \\
\text { de muito baixo peso }\end{array}$ & Sem associação entre ECN e transfusões \\
\hline
\end{tabular}

OR: odds ratio ou razão das chances; HR: hazard ratio; IC: intervalo de confiança; X2: teste de Newman-Keuls; df: grau de liberdade; p: valor p. 
em estimativas ajustadas (OR 2,01) quanto não ajustadas (OR 3,91). Os pesquisadores, porém, ressalvam que os neonatos que necessitaram de transfusão apresentavam, em geral, outros fatores considerados confundidores, como baixa IG, baixo peso, maior risco de PCA e maior propensão à ventilação mecânica. ${ }^{13-15}$ Esses fatores são encontrados nos dois casos aqui relatados.

Os estudos observacionais e os relatos de caso, apesar de sua incapacidade de determinar relação causa-efeito, são importantes para a sugestão de possíveis fatores causais para os processos patológicos e podem orientar a necessidade de desenvolvimento de desenhos de estudo com maior grau de evidência. Para tanto, tornam-se necessários estudos com amostra significativa e de metodologia adequada, por exemplo uma coorte prospectiva, como sugerido por Josephson et al. ${ }^{8}$ Entretanto, o acompanhamento dos casos descritos sugere que pacientes que apresentam fatores de risco para o desenvolvimento da ECN devem ser observados de forma mais rigorosa nas primeiras 48 horas após uma hemotransfusão, com o objetivo de detectar precocemente sinais sugestivos da doença e imediatamente iniciar-se seu tratamento, a despeito da mesma estar associada à transfusão em si ou à anemia que a justificou.

\section{REFERÊNCIAS}

1 Claud EC. Neonatal necrotizing enterocolitis - Inflammation and intestinal immaturity. Antiinflamm Antiallergy Agents Med Chem. 2009;8(3):248-59.

2 Alfaleh K, Al-Jebreen A, Baqays A, Al-Hallali A, Bedaiwi $\mathrm{K}, \mathrm{Al}$-Balahi $\mathrm{N}$ et al. Association of packed red blood cell transfusion and necrotizing enterocolitis in very low birth weight infants. J Neonatal Perinatal Med. 2014;7(3):193-8.

3 Christensen RD, Lambert DK, Henry E, Wiedmeier SE, Snow GL, Baer VL et al. Is "transfusion-associated necrotizing enterocolitis" an authentic pathogenic entity? Transfusion. 2010;50(5):1106-12.

4 Patel RM, Knezevic A, Keene S, Roback JD, Easley KA. Association of red blood cell transfusion, anemia, and necrotizing enterocolitis in very low-birth-weight infants ravi. JAMA. 2016;315(9):889-97.

5 Singh R, Visintainer PF. Association of necrotizing enterocolitis with anemia and packed red blood cell transfusions in preterm infants. J Perinatol. 2011;31(3):176-82.

6 Blau J, Calo JM, Dozor D, Sutton M, Alpan G, La Gamma EF. Transfusion-related acute gut injury: necrotizing enterocolitis in very low birth weight neonates after packed red blood cell transfusion. J Pediatr. 2011;158(3):403-9.

7 Maheshwari A. Immunological and hematological abnormalities in necrotizing enterocolitis. Clin Perinatol. 2015;42(3):567-85.

8 Josephson D, Wesolowski A, Bao G, Sola-Visner MC, Dudell $\mathrm{G}$, Castillejo MI et al. Do red cell transfusions increase the risk of necrotizing enterocolitis in premature infants? J Pediatr. 